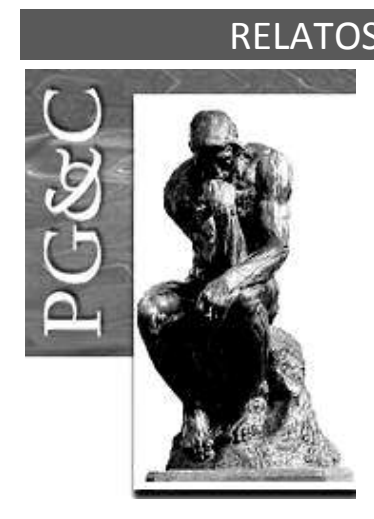

\title{
O ESTEREÓTIPO SMART CITY NO BRASIL E SUA RELAÇÃO COM O MEIO URBANO
}

\author{
Tharsila Maynardes Dallabona Fariniuk \\ Doutora em Gestão Urbana pela Pontifícia Universidade Católica do \\ Paraná, Brasil. \\ Professora do Centro Universitário UNIFACEAR, Brasil. \\ E-mail: tharsilamd@gmail.com \\ Marcela de Moraes Batista Simão \\ Doutora em Gestão Urbana pela Pontifícia Universidade Católica do \\ Paraná, Brasil. \\ E-mail: marcelamoraes.b@gmail.com@gmail.com \\ Rodrigo José Firmino \\ Doutor em Planejamento Urbano e Regional pela Newcastle University, \\ Inglaterra. Professor da Pontifícia Universidade Católica do Paraná, Brasil. \\ E-mail: rodrigo.firmino@pucpr.br \\ Juliana Helen Moreira Krebs Braga de Mendonça \\ Graduada em Arquitetura e Urbanismo pela Pontifícia Universidade \\ Católica do Paraná, Brasil. \\ E-mail: juhkrebs@yahoo.com.br
}

\begin{abstract}
Resumo
No Brasil, o uso do termo smart city tem sido geralmente adotado por projetos patrocinados por empresas estrangeiras ou desenvolvidos a partir de parcerias público-privadas. A utilização do termo nos projetos não possui uma lógica universal, pois o conceito pode denominar ações nas mais diversas áreas, e ser adaptado para servir a diferentes arranjos sociotécnicos. Essa discussão revela que parece existir certa confusão na adoção do termo smart city. Nesse sentido, este artigo pretende contribuir, de maneira exploratória e panorâmica, para a compreensão de possíveis manifestações de projetos de smart cities apropriados por cidades brasileiras, ante as interpretações e veiculações discursivas do conceito, a partir de diagnóstico das iniciativas assim denominadas nas 100 maiores cidades. Metodologicamente, a pesquisa estrutura-se em coleta de dados baseada em pesquisas por palavraschave e na categorização de dados de acordo com recortes tipológicos, geográficos e temporais. Os resultados mostraram que as iniciativas brasileiras autodenominadas smart city apresentam-se como ações relativas às mais diversas temáticas, refletindo a amálgama conceitual, e que estão voltadas principalmente para a promoção de eventos e feiras, para soluções de mobilidade e de segurança/vigilância, e para a digitalização de processos da administração pública. A pesquisa indica que os projetos estão, em grande parte, associados a um processo de reestruturação e de atualização de práticas com a utilização de novas tecnologias, e não necessariamente envolvidos com mudanças profundas na estrutura urbana ou no planejamento territorial.
\end{abstract}

Palavras-chave: Smart City. Gestão Urbana. Meio urbano. Cidades Brasileiras.

THE SMART CITY STEREOTYPE IN BRAZIL AND ITS RELATIONSHIP WITH THE URBAN ENVIRONMENT

\begin{abstract}
In Brazil, the use of the term smart city has generally been adopted by projects sponsored by foreign companies or developed from public-private partnerships. The use of this term does not follow a
\end{abstract}

Perspectivas em Gestão \& Conhecimento, João Pessoa, v. 10, n. 2, p. 159-179, maio/ago. 2020. DOI: http://dx.doi.org/10.21714/2236-417X2020v10n1p159

http://periodicos.ufpb.br/ojs2/index.php/pgc. ISSN: 2236-417X. Publicação sob Licença (cc) EY-NC-ND 
universal logic, because the concept can denominate actions in various areas, and is adopted to suit different sociotechnical arrangements. This discussion reveals some confusion in the adoption of the term smart city. In this sense, this article aims to contribute, in an exploratory and panoramic way, to the understanding of how possible manifestations of smart city projects are being appropriated by Brazilian cities, considering interpretations and discursive approaches of the concept, based on the characteristics of the 100 largest cities. We do so through a broad survey based on a specific collection of keywords, and in the categorization of data according to typological, geographical and temporal criteria. The results shows that Brazilian smart city initiatives are related to diverse themes, reflecting the conceptual amalgam, and are focused mainly on the promotion of events, urban mobility projects, security and surveillance tools, and for digitalization of processes of public administration. Our study indicates that the projects are largely associated with a process of restructuring and updating practices with the use of new technologies, and not necessarily involved with dramatic changes in the urban structure or territorial planning.

Keywords: Smart City. Urban Management. Urban environment. Brazilian Cities.

\section{INTRODUÇÃO}

A partir dos anos 1990, especialmente, ocorreu um processo de aceleração na disseminação de Tecnologias da Informação e Comunicação (TICS), principalmente por conta da popularização da Internet e das redes de telefonia celular, culminando com o desenvolvimento de smartphones e de fenômenos conhecidos como Big Data, Internet das Coisas (também denominada loT - Internet of Things), dentre outros. Nesse processo, as pessoas e os meios passaram a ser dotados de novos tipos de capacidades comunicacionais, que alteraram o comportamento humano e, por consequência, o modo de vida nas cidades. Isso, ao longo do tempo, levou à manifestação de novas formas de denominar as cidades. Nomenclaturas como "cidades virtuais" e "cidades digitais" tornaram-se recorrentes em estudos acadêmicos mais recentes e projetos urbanos (BESSELAAR, 2000; FIRMINO, 2004; AURIGI, 2005; MITCHELL, 1995).

Nesse cenário, o termo smart city emergiu e passou a ser adotado para definir cidades que fazem uso das tecnologias para atualizar, automatizar ou aprimorar sistemas e serviços (ALDAIRI; TAWALBEH, 2017; LLACUNA; COLOMER-LLINÀS; MELÉNDEZ-FRIGOLA, 2015). "Smart" significa inteligente, em tradução livre, embora a palavra "inteligente" não seja suficiente para representar integralmente a complexidade conceitual presente em "smart". Assim, inicialmente o conceito de smart city foi concebido para representar cidades que utilizavam plataformas tecnológicas e infraestrutura de TI - Tecnologia da Informação para prestação de serviços aos cidadãos. O conceito transformou-se, e hoje a smart city é considerada a partir das mais diferentes perspectivas, de modo que não há uma definição única para o conceito ou mesmo um consenso na literatura (ANGELIDOU, 2014; ALBINO; BERARDI; DANGELICO, 2015, ALDAIRI; TAWALBEH, 2017; BIBRI; KROGSTIE, 2017; CASSANDRAS, 2016).

No Brasil, o uso do termo smart city tem sido geralmente adotado por projetos patrocinados por empresas estrangeiras ou desenvolvidos a partir de parcerias públicoprivadas. A disseminação ocorre, ainda, por meio de feiras e exposições, onde o conceito é também associado a protótipos da indústria automobilística e da construção civil, e produtos originados em startups. A utilização dos termos nos projetos não possui uma lógica definida, pois o conceito pode denominar ações nas mais diversas áreas. Na ocasião da Copa do Mundo FIFA 2014, por exemplo, ocorreu a implantação de projetos voltados especialmente para vigilância, monitoramento e segurança, e alguns destes foram considerados como iniciativas smart city. Outras cidades denominaram dessa maneira projetos relacionados às energias

Perspectivas em Gestão \& Conhecimento, João Pessoa, v. 10, n. 2, p. 159-179, maio/ago. 2020. 
renováveis e à adaptação da malha elétrica urbana, como é o caso da cidade de Armação dos Búzios, balneário turístico do Rio de Janeiro

Essa discussão revela que parece existir certa confusão na adoção do termo smart city. Há dificuldade em reconhecer o que é ou não, de fato, inteligente na gestão das cidades. A própria utilização do termo pode indicar contrariedades; é questionável se o conceito de inteligência, como é usado para seres humanos, pode ser atribuído para objetos (e cidades) da mesma maneira (SALGADO, 2016). Além disso deve-se considerar que nas dinâmicas do espaço urbano as relações de poder estão cada vez mais relacionadas ao uso das tecnologias uma vez que o poder está intrínseco a todos os mecanismos da sociedade (FOUCAULT, 2008) e isso também influencia a concepção do smart, a partir da criação de novas racionalidades (KLAUSER; PAASCHE; SÖDERSTRÖM, 2014; LUQUE-AYALA; MARVIN, 2015). Sabe-se, porém do enorme potencial comercial do rótulo smart city, o que tem sido explorado em vários tipos de mercado e organizações.

Nesse sentido, a presente pesquisa objetiva compreender, de maneira exploratória e panorâmica, de que modo se desencadeia o fenômeno das smart cities nas cidades brasileiras, ante as interpretações e veiculações discursivas do conceito, a partir de diagnóstico das iniciativas assim denominadas nas 100 maiores cidades. Além disso, este artigo propõe: a) sintetizar teórica e conceitualmente as definições e interpretações do conceito de smart city, sob a perspectiva da representatividade para a gestão urbana; b) analisar a aplicabilidade do conceito de smart city em projetos para as maiores cidades brasileiras, a partir da construção do panorama da implementação e de avaliação de iniciativas.

Essa investigação origina-se em um projeto maior de pesquisa, em nível de doutorado, que visou investigar a construção discursiva em torno do fenômeno das smart cities no Brasil. Tal estudo iniciou sob a hipótese inicial que de que o conceito está sendo aqui implementado de um modo a contemplar principalmente uma simples atualização das práticas de governança e de gestão por meio das tecnologias, não necessariamente as adotando como instrumentação de aprimoramento estratégico.

Este artigo divide-se em quatro partes, além dessa introdução. A primeira parte estabelece as balizas teóricas pautadas por definições de smart e smart city no campo dos estudos urbanos, a partir do desenho de um breve panorama sobre o histórico de adoção de diferentes nomenclaturas, passo importante para traçar os perfis de projetos desenvolvidos sob elas. A segunda parte dedica-se a descrever a metodologia adotada para o estudo empírico dos casos de smart city no Brasil. A terceira seção compreende uma cuidadosa discussão dos resultados a partir dos dados de categorização, período de implementação e distribuição geográfica das iniciativas levantadas. Por fim, a conclusão lança reflexões sobre o fenômeno de smart cities no Brasil a partir do panorama de desenvolvimento até o momento de finalização dessas pesquisas.

\section{A “SMARTIFICAÇÃO" DO URBANO: UM BREVE HISTÓRICO SOBRE TERMOS ADOTADOS}

A partir da década de 1990, as novas formas de comunicação permitidas pelo advento e avanço da informática e telecomunicações alteraram os modos de produção e trabalho nas sociedades capitalistas do fim do século XX. O desenvolvimento de computadores em rede, por exemplo, gerou uma situação de certa independência dos meios de transporte por exemplo, a partir da criação de postos de trabalho à distância (teleworking) e de custos de operações relativamente baixos. A cidade que se construía neste contexto recebia a denominação de "Cidade Informacional", e, quando a informação passava a ser compreendida como meio para diversificação e criatividade na economia, era comum a utilização do termo "Cidade do Conhecimento" (ZHAO, 2010). Esses conceitos foram bastante aproveitados pela indústria do entretenimento que, em meados dos anos 1990 e 2000, criou jogos de simulação

Perspectivas em Gestão \& Conhecimento, João Pessoa, v. 10, n. 2, p. 159-179, maio/ago. 2020. 
da realidade urbana - como Second Life e The Sims - com possibilidades de interação de pessoas em formato de avatares e com atividades semelhantes às realizadas no cotidiano. Nesse contexto as cidades passaram a ser também entendidas como "virtuais", associando o urbano à tecnologia, com recursos de interação entre pessoas e dados num ambiente como um site ou portal (EISENBERG, 1999). As comunidades online foram fundamentais para a disseminação do termo "cidade virtual", pois serviram como ferramentas de interação e como potencializadoras das identidades locais (DONATH, 1996).

Este fenômeno é parte do que Lemos (2002) denomina de cibercultura. Trata-se da cultura gerada em torno das ações que ocorrem no ciberespaço. A mistura desta concepção urbana distópica com o ciberespaço é o que Boyer (1992) e Gandy (2005) denominam cybercity (também denominada cybercidade). Trata-se de um entendimento do urbano multilinear e não sequencial, permitido no meio eletrônico. Mitchell (2003), explica esta ideia fazendo uma analogia com o homem Vitruviano ${ }^{1}$, estático e contido num círculo perfeito e definido. O cidadão cyborg ${ }^{2}$, ao contrário, possui perspectivas pessoais e responde imediatamente às ocorrências do ambiente, pois possui uma estrutura corporal com limites permeáveis pelas ramificações de uma rede de conexões.

É comum que exista, ainda, uma equalização entre os termos "virtual", "digital" e "cibernético"(AURIGI, 2005). Embora exista a confusão de nomenclaturas, na realidade o "virtual" e o "digital" são utilizados para representar o mesmo fenômeno: ambos refletem uma nova forma de apropriação urbana a partir de uma inflexão causada pelas tecnologias (cada vez mais interativas). O que é digital não apresenta contradição com o que é real; o que ocorre é que o concreto é rígido e tangível, enquanto o digital remete à volatididade e à invisibilidade (NETTO, 2014). Neste sentido, a noção de cidade digital, utilizada pela primeira vez em 1993 (BESSEELLAR, 2003) pode ser facilmente associada a um tipo de aplicação específica de sistemas de $\mathrm{Tl}$ e de informações, que conferem uma identidade para serviços online. Assim, cidades digitais são ambientes que podem constituir comunicação entre cidadãos e gestão (AURIGI, 2005).

A presença e proliferação das mais diversas tecnologias nos ambientes tende a remeter a ideia de espaços desenvolvidos, mas também torna visível - ou cria - problemáticas até então desconhecidas. A disseminação de tecnologias cada vez mais invisíveis e pervasivas confere às pessoas a participação em uma rede onde compartilhamentos são capazes de influenciar comportamentos. Assim, tudo o que compõe o cotidiano urbano - mobilidade, circulação, segurança pública, saúde, etc. - pode tornar-se dados na rede, objetos de troca entre cidadãos. Hollands (2008) atenta para o fato de que, embora a tecnologia gere uma série de possibilidades, ela não possui como aspecto primordial a capacidade automática de criar comunidades mais inteligentes, mas sim de criar condições de adaptabilidade e de empoderamento humano para o incremento do meio. Nesse contexto emerge um conceito que vem ganhando cada vez mais espaço nos projetos urbanos contemporâneos: A loT, conceito que determina que objetos estão interconectados em rede mundial, segundo códigos que alteram profundamente a relação entre humanos e tecnologias (INFSO, 2008). Em outras palavras, significa que objetos, sensores e redes, tornam-se sensíveis e sensitivos, sendo direcionados para responder de forma automática às demandas do contexto (LEMOS, 2013).

\footnotetext{
${ }^{1}$ Conceito apresentado por Leonardo da Vinci no século XV, em que se apresenta a figura de um homem inscrito em formas geométricas de perfeitas proporções; é considerado um dos principais símbolos do Iluminismo (FLOCH-PRIGENT, 2008).

${ }^{2}$ Cyborg, termo disseminado pela literatura ciberfeminista de Donna Haraway - entre outros autores associa a subjetividade etimológica e híbrida das noções de um organismo substantivo e de um adjetivo cibernético (SOUZA; CATALÃO, 2016).
} 
Esse é o contexto em que emerge, também, o conceito de smart city. Trata-se de um entendimento da cidade contemporânea sendo transformada e enriquecida com a presença de novas tecnologias, mais aberta a soluções e mais preparada para responder às demandas sociais.

A smart city busca concatenar inteligência humana, inteligência coletiva e inteligência artificial. A primeira camada é física, composta pelo espaço, aglomerações e pessoas. Trata-se da utilização do capital intelectual de uma comunidade para desenvolver um planejamento que otimize as condições, o bem-estar e os desafios urbanos (KOMNINOS, 2011). Em geral, os autores divergem em relação ao início exato de utilização do termo smart city, embora exista um consenso de que ele começa a ser disseminado a partir dos anos 1990 (KOMNINOS, 2011; LLACUNA; COLOMER-LLINÀS; MELÉNDEZ-FRIGOLA, 2015; ALBINO; BERARDI; DANGELICO, 2015), na tentativa de discutir questões muito presentes na época, como a flexibilidade produtiva, a polarização social e os polos tecnológicos (KOMNINOS, 2011).

Alguns autores divergem na utilização do termo smart city como alicerce a duas tipologias de estratégias: uma que é mais tecnocrática - na qual a tecnologia controla os fluxos, é invasiva e pervasivas - e outra que é mais antropocêntrica - focada na mobilização de ideias, no capital humano e no aprimoramento da governança (GRAHAM; MARVIN, 1996; KITCHIN, 2014). No entanto, é importante considerar que esses enquadramentos teóricos não são absolutos, e que, portanto, diferentes autores podem transitar entre uma ou outra abordagem, considerando também a atualização de pensamento e oscilações ao longo do tempo. Isso só corrobora para reforçar a dificuldade de precisão do conceito (FARINIUK, 2018).

Um dos conceitos mais difundidos atualmente para as smart cities é o que pressupõe essa cidade tornando-se mais inteligente a partir da ação em seis esferas: a governança, a economia, a qualidade de vida, o meio ambiente, a mobilidade e o cidadão. Nessa abordagem, fatores como a existência de um espírito inovador, a eficiência, a otimização de recursos e a criação de uma consciência coletiva de proatividade são fundamentais para integrar as seis dimensões (GIFFINGER et al., 2007; TUWIEN, 2016). Sendo assim, o conceito de smart city também é significativamente difundido sob a ótica de uma eficaz e otimizada associação entre cidadãos ativos e pensantes e tecnologias inteligentes e estrategicamente utilizadas, relação na qual é de fundamental importância a atuação de cidadãos engajados no processo de definição de agendas urbanos (CASSANDRAS, 2016; ALBINO; BERARDI; DANGELICO, 2015; BASTOS; MITTERMAYER, 2016).

Uma abordagem corporativa, conduzida por interesses econômicos, também está presente no conceito. A popularização do discurso sobre as smart cities se manifesta também, como uma disputa de mercado entre empresas, que passam a veicular suas imagens ao conceito de "inteligência" urbana (KLAUSER; PAASCHE; SÖDERSTRÖM, 2014), cujo discurso origina-se na lógica capitalista que prevê, geralmente, intervenções urbanas mais pontuais e até mesmo especulativas (MASCARENHAS e BORGES, 2008) - é o que Harvey (2005) denominou como modelo de cidade empreendedora (entrepreneurial city). Nesse tipo de entendimento, o espaço urbano passa a ser visto como um campo em expansão com foco no mercado, e, assim, a disseminação do conceito reflete também eventuais abordagens políticas, repletas de relações de poder ${ }^{3}$ e interesses (VANOLO, 2014). O reflexo prático desse processo é a movimentação financeira que esse nicho de mercado gera. Uma pesquisa da Navigant Research sobre o tema estima que até 2028 o mercado de tecnologias para smart cities irá movimentar até 263 bilhões de dólares - valor que atualmente gira em torno de 100 bilhões de dólares (BUSINESSWIRE, 2019).

\footnotetext{
${ }^{3}$ De acordo com Foucault (2008), as relações de poder não são necessariamente aquelas ligadas ao Estado-Nação, e sim ao saber acerca de uma população; nesse sentido, o poder está em todos os mecanismos que envolvem a sociedade, não podendo estar ausente de nenhum processo.
}

Perspectivas em Gestão \& Conhecimento, João Pessoa, v. 10, n. 2, p. 159-179, maio/ago. 2020. 
Segundo Peck e Tickell (2002) a lógica produtivista que permeia esse processo posiciona as cidades com uma prioridade de desenvolvimento econômico, para somente então realizar ações que visem ao bem-estar social. Há, portanto, uma tendência a mais ações de foco competitivo e menos ações visando a coletividade. Desse modo, o próprio conceito de smart cities torna-se uma espécie de "marca" ou "rótulo" comercial, a exemplo da capitalização criada pela empresa IBM nos anos 2010 (ALIZADEH et al, 2017). Nesse sentido, pode-se observar fragilidades tanto no âmbito do discurso, muito atrelado ao marketing urbano - smart cities para quem? - a exemplo do que questiona Santaella (2016), quanto no âmbito da estruturação propriamente dita dos projetos.

A respeito do discurso, Maček (2019) informa que o marketing nas smart cities é realizado por dois grupos: a autoridade da cidade (e seus pares), e os provedores de soluções; os primeiros para mostrar - aos eleitores - que estão adotando "soluções" para os problemas da cidade, e os últimos para ampliar seu reconhecimento no mercado de tecnologias de gestão. Nesse sentindo, a efetivação das ações de marketing considera a alocação de capital humano preparado para a competitividade de produtos e serviços. Quanto à estrutura, Greenfield (2013) estabelece uma série de críticas sobre uma rigidez tecnológica tão severa que não permite à cidade a flexibilidade necessária para adaptações mais orgânicas e espontâneas, frente a demandas. $\mathrm{O}$ autor questiona, entre outras coisas, o real papel da dita cidade inteligente para o aproveitamento de recursos de dados em prol dos cidadãos, principalmente as populações mais vulnerabilizadas e excluídas.

Assim, não se trata de pensar a cidade inteligente a partir de uma desvalorização das estruturas tecnológicas, conforme pontua Delarbre (2017), mas sim de entendê-las como as ferramentas que são, a partir das oportunidades e resistências que oferecem ao meio urbano.

\section{METODOLOGIA}

Diante da relativa novidade do fenômeno, falta de consenso em sua definição, e o entusiasmo com que essas ideias têm se propagado, a pesquisa foi realizada com o intuito de levantar evidências empíricas sobre o movimento de smart cities no Brasil, a partir de uma observação de cunho exploratório e panorâmico. Esse processo é metodologicamente delineado como um estudo de caráter quali-quantitativo transversal, ou seja, relacionado com um recorte temporal definido e pontual (FONTELLES, M.; SIMÕES; FONTELLES, S., 2009). A técnica adotada foi um survey, ferramenta utilizada para compreender processos sociais, que consiste em uma sistematização e padronização de dados a partir de uma determinada amostra (ROSSI; WRIGHT; ANDERSON, 2013).

Levantou-se o panorama de iniciativas smart cities nas 100 maiores cidades brasileiras (quanto à população, segundo dados da projeção populacional do IBGE de 2016), com especial atenção às capitais dos 26 estados mais o Distrito Federal.

Optou-se por essa seleção por três razões: (a) representatividade simbólica quantitativa que permite a construção do panorama do que está sendo feito no Brasil; (b) o fato de grandes cidades serem especialmente relevantes para representar as diversas preocupações urbanas, ao potencializarem a complexidade, falta ou má-administração da infraestrutura urbana - fator determinante para a gestão do território (ROLNIK; SOLMEKH, 2002); e (c) o fato de as capitais brasileiras concentrarem cerca de $40 \%$ da população nacional.

A coleta de dados foi realizada a partir de busca nas seguintes fontes: a)Site das prefeituras municipais; b) Site dos governos estaduais; c) Artigos em portais de periódicos (CAPES, Scielo e Redalyc); d) Google Scholar (artigos provenientes de outras bases); e) Portais de Notícias (G1 e O Globo); f) Mídias sociais da prefeitura, quando houver (Facebook e/ou Twitter); g)Outros portais de notícias, direcionados a partir do motor de busca do Google. 
Nessas fontes, a busca foi realizada a partir das seguintes combinações de palavraschave:

a) "nome da cidade" and "smart cities" (incluindo também o singular "smart city"); inteligente");

b) "nome da cidade" and "intelligent city" (também em português, "cidade

c) "nome da cidade" and "smart cities" and "categoria do projeto" (onde "categoria" significa uma dimensão de atuação no espaço urbano, como por exemplo: mobilidade, governança, meio ambiente, etc.).

Todas as notícias resultantes dessa pesquisa alimentaram sistematicamente uma planilha até a saturação, ou seja, conduzida até o momento em que não exista mais nenhuma informação nova, ou dado que já tivesse sido coletado em fases anteriores e que pudesse contribuir para a compreensão do fenômeno (MARTINS, 2006).

Considerou-se, para formatação dessa planilha, a categorização dos projetos de acordo com o ano de implantação, a esfera de implementação (Municipal, Estadual, Federal ou combinação destas), a secretaria responsável pela idealização/implementação do projeto, e as instituições parceiras (quando aplicável). Além disso, categorizou-se o projeto com uma palavra-chave, em muitos casos apresentada na própria notícia, ou atribuída a partir da descrição da notícia.

Após o processo de tabulação e concatenação dos dados, verificou-se a existência de 16 tipologias de palavras, que se transformaram, assim, em categorias de análise.

A análise de dados iniciou com a elaboração de gráficos a partir dos dados tabulados, a fim de facilitar visualmente a compreensão. Primeiramente realizou-se uma análise de dados quantitativa, segundo a qual foi possível observar de que modo os projetos distribuem-se geograficamente no território, indicando locais de maior predominância e/ou de concentração.

Em segundo lugar, os projetos foram relacionados conforme ano de implantação, avaliando se há caráter recente nas iniciativas. Um segundo momento visou a análise também qualitativa dos dados, de forma a verificar, por exemplo, quais são as áreas de maior interesse dos projetos, de acordo com sua descrição. Os resultados apresentarão essa mesma sequência analítica, a fim de tornar o entendimento da pesquisa mais didático.

\section{RESULTADOS: CARACTERIZANDO INICIATIVAS SMART CITIES NAS MAIORES CIDADES BRASILEIRAS}

A partir da metodologia aplicada, foram identificados 276 projetos distribuídos em 86 cidades brasileiras. Um total de 14 cidades não apresentaram nenhum projeto relacionado à busca realizada com as palavras-chave. São elas: São Gonçalo (RJ), Ananindeua (PA), Belford Roxo (RJ), Serra (ES), Macapá (AM), São João de Meriti (RJ), Betim (MG), Diadema (SP), Carapicuíba (SP), Caucaia (CE), Itaquaquecetuba (SP), Petrolina (PE), Ribeirão das Neves (MG) e Guarujá (SP). A figura 1 apresenta a distribuição das 86 cidades em que foram identificadas iniciativas smart city, onde cada pin representa a presença de projetos assim denominados. 
Figura 1 - Distribuição das cidades com projetos veiculados como smart city

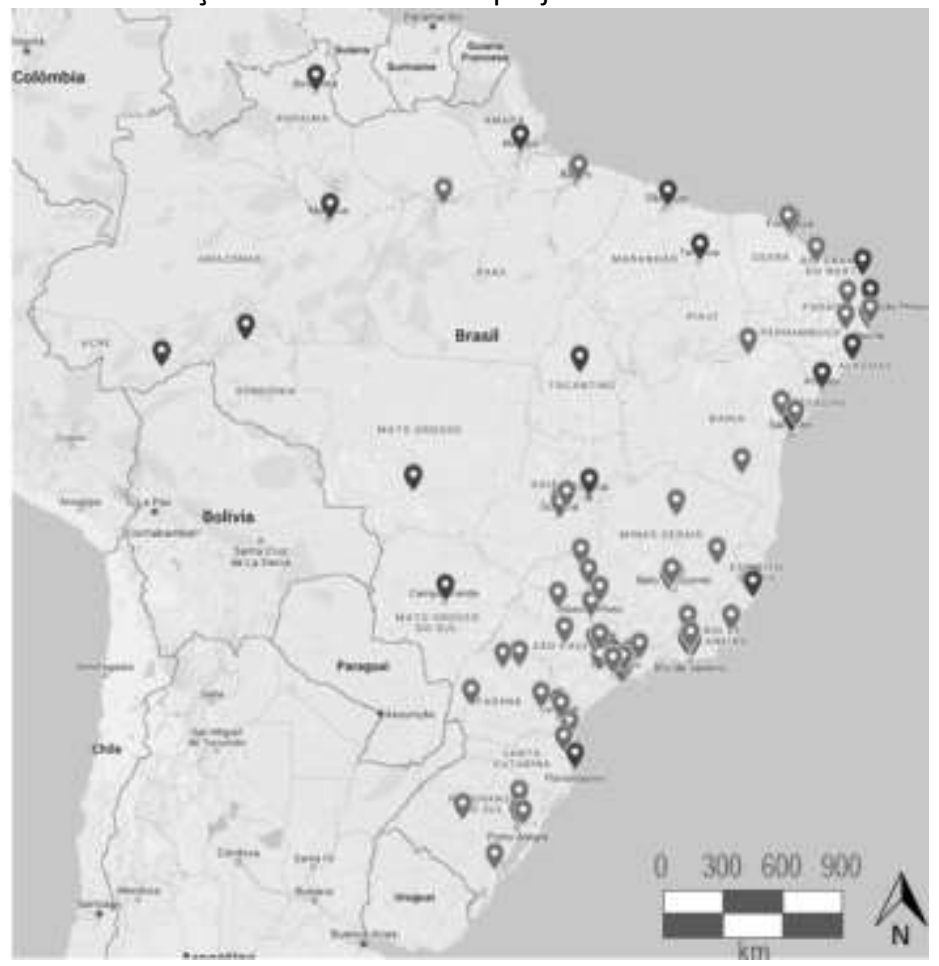

Fonte: Os autores (2019), com auxílio da ferramenta Google My Maps, a partir da projeção populacional para 2018 (IBGE, 2019)

Entre as capitais, Recife figura com a maior quantidade de projetos mencionados, seguida por São Paulo, Rio de Janeiro e Curitiba. O caso de Recife é especialmente interessante por apresentar diversas iniciativas oriundas de uma mesma macro-ação: o projeto Porto Digital. O Porto Digital é um espaço voltado para empreendedorismo onde se investiu, inicialmente (2001), 94 milhões de reais. Áreas antigas e históricas da cidade foram requalificadas para a utilização de tecnologias que alteraram o espaço urbano e as relações de poder entre o poder público e o privado. Nesse caso, em especial, o uso do marketing contribuiu para promover a cidade como polo inovador, digital e tecnológico, o que reforça a ideia de mercantilização do conceito de smart city. Esse é um processo definido por Kitchin (2014) como a smart city conceituada por empresas e vendida em "pacotes" de inovação. Considerando que o polo digital passou a configurar um dos principais empreendimentos urbanos da cidade de Recife - abrigando inclusive imóveis de luxo em seus arredores evidencia-se a lógica de mercado presente também, no processo, conforme Mascarenhas e Borges (2008).

Observa-se também uma relativa concentração de iniciativas nas regiões Sudeste e Sul do país, tradicionalmente mais acumuladoras de riquezas e de capital industrial. Isso reflete uma face que a smart city pode assumir, muitas vezes: o foco na economia neoliberal e globalizada, em que as tecnologias são implantadas no espaço urbano com a finalidade de aumentar um fluxo de investimentos internacionais.

Cada um dos projetos analisados recebeu uma identificação por palavra-chave, apresentada no próprio meio de divulgação do projeto (uma notícia, por exemplo), ou a partir da descrição (vide item metodologia).

Esse processo resultou em dezesseis categorias, diferenciadas a partir dessa correlação de termos (Quadro 1). O Gráfico 1 apresenta a distribuição das iniciativas smart city encontradas, de acordo com essa tipificação. 
Tharsila Marinardes D. Fariniuk; Marcela de Moraes B. Simão; Rodrigo José Firmino;

Juliana Helen Moreira K. Braga de Mendonça

Quadro 1 - Descrição das dezesseis categorias de projetos

\begin{tabular}{|c|c|}
\hline Categoria & Descrição \\
\hline Evento | Feira & $\begin{array}{l}\text { Qualquer tipo de evento relacionado à discussão de ideias para smart cities, } \\
\text { à divulgação de projetos ou à oferta de produtos para este fim. Nesta } \\
\text { categoria estão inclusos simpósios, workshops, congressos, seminários, } \\
\text { feiras e hackathons. }\end{array}$ \\
\hline Mobilidade & $\begin{array}{l}\text { Iniciativas voltadas para o incremento da modalidade urbana, relacionadas a } \\
\text { qualquer tipo de modal de transporte (carro, ônibus, metrô, bicicleta, etc), a } \\
\text { aplicativos para celular associados a esses modais ou à instalação de } \\
\text { tecnologias para o aprimoramento dos modais (por exemplo, semáforos } \\
\text { inteligentes, pontos de ônibus inteligentes, etc). }\end{array}$ \\
\hline $\begin{array}{l}\text { Vigilância | Segurança } \\
\text { Pública }\end{array}$ & $\begin{array}{l}\text { Qualquer ação voltada para o controle e monitoramento do espaço urbano a } \\
\text { partir da instalação de câmeras/sensores ou voltada para o incremento das } \\
\text { forças de segurança a partir da inserção de tecnologias de controle, } \\
\text { rastreamento, etc. }\end{array}$ \\
\hline $\begin{array}{l}\text { Digitalização de } \\
\text { processos e práticas }\end{array}$ & $\begin{array}{l}\text { Nessa categoria enquadram-se iniciativas de acesso digital, de oferta de rede } \\
\text { banda larga e WiFi e de disponibilização de serviços municipais online } \\
\text { (anteriormente disponíveis apenas pessoalmente, fisicamente ou via } \\
\text { telefone). }\end{array}$ \\
\hline $\begin{array}{l}\text { Meio Ambiente } \\
\text { Sustentabilidade }\end{array}$ & $\begin{array}{l}\text { Iniciativas voltadas para a preservação do meio ambiente, incluindo gestão } \\
\text { de resíduos, gestão eficiente e sustentável de energia e utilização de fontes } \\
\text { renováveis. }\end{array}$ \\
\hline Transparência & Ações de disponibilização de contas públicas e portais de dados abertos. \\
\hline $\begin{array}{l}\text { Parque Tecnológico | } \\
\text { Ecossistema de } \\
\text { Inovação }\end{array}$ & $\begin{array}{l}\text { Projetos de implantação e manutenção de áreas geograficamente } \\
\text { delimitadas para o funcionamento de ações de planejamento voltadas para a } \\
\text { inovação e produtos, fomentadas pela parceria entre a prefeitura e } \\
\text { instituições diversas (incluindo iniciativa privada e universidades). }\end{array}$ \\
\hline $\begin{array}{l}\text { Governança | Gestão } \\
\text { | Planejamento }\end{array}$ & $\begin{array}{l}\text { Iniciativas voltadas para o uso da tecnologia como incremento para a gestão } \\
\text { propriamente dita, incluindo aprimoramento dos sistemas digitais internos, } \\
\text { processamento de dados, softwares de planejamento urbano, etc. }\end{array}$ \\
\hline Educação | Cidadania & $\begin{array}{l}\text { Ações voltadas para o compartilhamento de conhecimento entre governo e } \\
\text { população, informativos da cidade e planejamento do espaço urbano. }\end{array}$ \\
\hline $\begin{array}{l}\text { Capacitação } \\
\text { Profissional }\end{array}$ & $\begin{array}{l}\text { Oportunidades de realização de cursos nas mais diversas áreas, } \\
\text { especialmente voltados para o uso de novas tecnologias. São cursos } \\
\text { ofertados pelas prefeituras, somente, ou em parceria com instituições } \\
\text { privadas ou escolas/universidades. }\end{array}$ \\
\hline $\begin{array}{l}\text { Empreendedorismo | } \\
\text { Inovação }\end{array}$ & $\begin{array}{l}\text { Ações voltadas para o incentivo ao empreendedorismo e inovação (de } \\
\text { produtos e/ou processos) nas comunidades. Esta categoria ocorre em } \\
\text { separado da categoria "Parque Tecnológico" por se tratar de iniciativas de } \\
\text { menor porte, não necessariamente associadas a uma área específica. }\end{array}$ \\
\hline Saúde & $\begin{array}{l}\text { Iniciativas para o aprimoramento do sistema público de saúde, a partir da } \\
\text { inserção de tecnologias digitais (bases unificadas, agendamento de consultas } \\
\text { online, etc). }\end{array}$ \\
\hline Turismo & $\begin{array}{l}\text { Ações de incremento da atividade, no que diz respeito ao aperfeiçoamento } \\
\text { da experiência do turista a partir do uso de tecnologias como realidade } \\
\text { aumentada. }\end{array}$ \\
\hline Infraestrutura Urbana & $\begin{array}{l}\text { Iniciativas de implantação, requalificação ou revitalização de elementos de } \\
\text { infraestrutura urbana como mobiliário urbano, calçadas, postes de } \\
\text { iluminação, etc. }\end{array}$ \\
\hline Habitação Social & $\begin{array}{l}\text { Ações para a construção e/ou melhoria de áreas de habitação de interesse } \\
\text { social. }\end{array}$ \\
\hline
\end{tabular}

Perspectivas em Gestão \& Conhecimento, João Pessoa, v. 10, n. 2, p. 159-179, maio/ago. 2020. 
Tharsila Marinardes D. Fariniuk; Marcela de Moraes B. Simão; Rodrigo José Firmino; Juliana Helen Moreira K. Braga de Mendonça

\begin{tabular}{|l|l|}
\hline Patrimônio Histórico & $\begin{array}{l}\text { Ações de preservação do patrimônio histórico construído e/ou memória } \\
\text { local. }\end{array}$ \\
\hline
\end{tabular}

Fonte: Os autores (2019)

Gráfico 1- Distribuição do número de projetos, por área temática

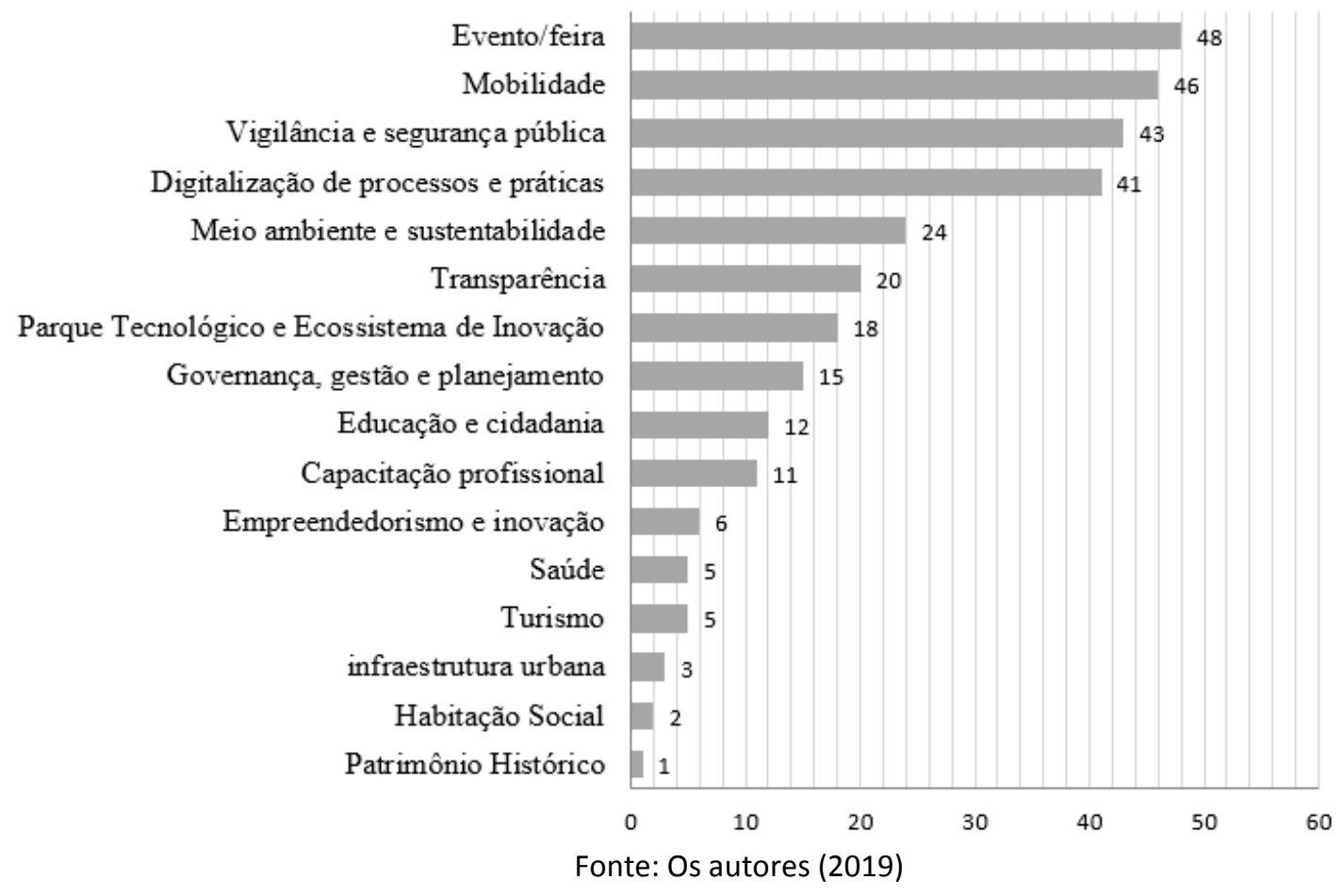

Pode-se observar que a categoria evento/feira concentra o maior número de iniciativas, o que sugere ao mesmo tempo uma preocupação com a discussão e a emergência do conceito de smart city, e uma dificuldade de extrapolação das ideias para além da exposição e da discussão. Uma especulação a ser feita nesse sentido é a de que eventos são iniciativas geralmente fáceis de implementar, com baixo custo, exigindo pouca responsabilidade futura. Essa situação reflete uma ação exploratória em torno do conceito de smart city, não sendo ainda, efetivamente, uma forma de apropriação tecnológica. No entanto, entende-se que o evento/feira agrega visibilidade para a cidade sede, o que constitui, ao menos em parte, uma visão de marketing urbano apontada por Maček (2019). Em segundo e terceiro lugares aparecem as categorias mobilidade e vigilância/segurança pública, respectivamente. Essas categorias concentram, juntas, 89 projetos, o que representa $32 \%$ do total. Isso sugere que o entendimento do conceito de smart city está bastante relacionado à solução de duas das principais demandas urbanas brasileiras (mobilidade e segurança). Klauser, Paasche e Söderström (2014) argumentam que as novas dinâmicas de software e tecnologias usadas para controlar o espaço urbano, focadas em sistemas de segurança, monitoramento e vigilância, estão transformando as relações de poder em um novo tipo de normatização, racionalização e gestão da vida. Defendem, ainda, que a teoria de Foucault vai além de meros estudos sobre os atos de poder diante das novas tecnologias e se concentram em movimentos detalhados que as tecnologias utilizam, por meio das microfísicas do poder. Sendo assim, o poder é compreendido nas suas unidades micro, evidenciando que a governamentalidade na smart city se manifesta por diferentes formas de poder, mas que a essência do poder, que é controlar, não foi perdida.

Perspectivas em Gestão \& Conhecimento, João Pessoa, v. 10, n. 2, p. 159-179, maio/ago. 2020. 
O crescimento das cidades, bem como os novos padrões de vida exigem a sistematização e a otimização dos serviços urbanos. Ao mesmo tempo, a inserção de novas tecnologias no cotidiano traz novas possibilidades. Com isto, a cidade torna-se um palco de disputas por recursos, por novas tecnologias e por capital humano na tentativa de obter destaque no cenário mundial - processo que atrela novos significados e novas relações de poder inerentes ao conceito de cidade inteligente.

Além disso, é interessante notar que as quatro primeiras categorias representam basicamente dois terços do total.

Nesse caso, os resultados apontam que a mobilidade passa a ser compreendida como um dos aspectos urbanos que mais impactam a vida cotidiana e portanto, exercem impacto também nas relações de poder. A mobilidade envolve uma série de tecnologias que problematizam o poder na sociedade, deixando de ser uma área apenas técnica e sendo, também, social e política (URRY, 2000). Os resultados na área da segurança pública, por sua vez, enfatizam a importância do "policiar" nas áreas urbanas (FOUCAULT, 2008).

É, também, significativo o número de iniciativas voltadas para a digitalização de processos e práticas. $O$ valor elevado indica a tendência de reconhecimento do conceito de inteligência urbana associado ao que é eletrônico/digital.

Inferências podem ser feitas a esse respeito, no sentido de que a digitalização ocorre por uma busca de eficiência interna, podendo muitas vezes ser uma demanda dos próprios funcionários públicos que visam aprimorar as condições e velocidade do trabalho. Nesse sentido, o aperfeiçoamento reforça um discurso de visibilidade, exige pouco compromisso e dificilmente provoca reações contrárias. Esse também pode ser um ato relativo à abordagem mais elementar da relação meio-tecnologia proposta por Graham \& Marvin (1996). Isso ocorre quando apenas vislumbra-se (ou discute-se em nível mais superficial) os impactos das tecnologias no meio; a digitalização, nesse caso, representa a mera substituição dos aparatos físicos pelos digitais.

Em diversas cidades, a disponibilização de sinal WiFi em espaços públicos, por exemplo, é a primeira - e muitas vezes, experimental - iniciativa municipal de absorção das novas tecnologias. Este resultado pode sugerir, também, uma preocupação com oferta básica de serviços eletrônicos, e indica os primeiros passos de um processo de estruturação digital que parece ser, ainda, necessário em muitas localidades, embora não seja desejável como única finalidade (GUERREIRO, 2006). Esta ação ainda pode ser caracterizada como sendo parte de uma perspectiva tecnocrática, (KITCHIN, 2014) pois concentra-se na disponibilidade de meios técnicos, embora possa ter a intenção declarada de evoluir para uma abordagem antropocêntrica, prevendo o uso do recurso para ampliar a qualidade de vida, através da disponibilidade de serviços municipais pelo sistema.

O processo corrobora a noção de que a sociedade tende a buscar incessantemente a inclusão digital e ferramentas cada vez mais capazes de auxiliar no gerenciamento do espaço e de interferir nas interações humanas (CALZADA; COBO, 2015). Ainda, de acordo com Graham e Marvin (1996) estas ações podem ser caracterizadas como sendo uma coevolução, pois visam ampliar o leque de possibilidades, para que meio e tecnologias possam evoluir em paralelo.

Estes resultados inferem discussões a respeito da hipótese inicial de investigação, a relembrar: $O$ conceito de smart city no Brasil é, ainda, mais frequentemente associado à digitalização de dados e processos? Isso ocorre em maior escala em relação a processos de otimização, eficácia e integração entre setores e serviços urbanos?

O Gráfico 1 sugere que isso ocorre em certa medida, uma vez que a categoria relacionada à digitalização de processos e práticas aparece como frequente, em quarto lugar. No entanto, a predominância de iniciativas voltadas para feiras, eventos e hackatons sugere que pode existir, de fato, uma preocupação - ainda que apenas a nível intencional - com soluções para otimização de recursos e de demandas urbanas diversas. Observa-se que os 
itens do topo da lista estão mais associados a uma perspectiva tecnocrática; à medida que as ações aparecem em menor quantidade, sobressaem os itens relacionados a uma perspectiva mais antropocêntrica (como apresentado anteriormente nas possibilidades de abordagem do conceito propostas por Kitchin (2014) e Graham e Marvin (1996)).

Nesse sentido, pode-se afirmar que o fenômeno de smart cities desencadeia-se no Brasil como um processo de reestruturação e de atualização de práticas com a utilização de novas tecnologias, e não necessariamente como um modelo totalmente original de gestão urbana ou de planejamento territorial? Pode-se inferir a partir dos resultados que, pode existir, de fato, uma tentativa de atualização de práticas com a utilização de novas tecnologias, dada a quantidade de projetos voltados para a vigilância e monitoramento e digitalização de processos e práticas. Isso reflete o estágio de cada situação, no processo do tecnocêntrico para o antropocêntrico.

Observa-se que, em comparação às outras categorias, as dimensões relacionadas à habitação, infraestrutura, saúde, patrimônio e turismo são encontradas em menor número. Algumas especulações podem ser feitas nesse sentido. Em primeiro lugar, pode existir uma incidência menor de programas municipais voltados à habitação por esse ser um setor de atuação majoritariamente da esfera federal (especialmente a partir de iniciativas como o Programa Minha Casa, Minha Vida). Em segundo lugar, infraestrutura é uma tipologia de projeto que pode dispersar-se por entre outras categorias, já que é uma temática ampla, o que pode explicar a pouca incidência. Em terceiro lugar, a baixa incidência na categoria saúde pode ser explicada porque as iniciativas desse setor podem estar também inclusas na categoria digitalização de processos e práticas, em especial pela quantidade de aplicativos destinados à marcação de consultas e vistas a exames médicos. A categoria patrimônio, por sua vez, pode ser vista muitas vezes só como forma de incentivar o turismo. Essa, por sua vez, pode possuir baixa incidência por estar bastante atrelada à iniciativa privada, demandando menos atenção governamental do que outras demandas urbanas.

O recorte de iniciativas smart city aqui apresentado também pode ser observado relativamente à questão temporal. Os resultados apontam projetos implementados entre os anos de 2004 a 2017. O Gráfico 2 apresenta a distribuição das 276 iniciativas por ano, com respectivas taxas de crescimento entre os anos:

Gráfico 2 - Distribuição das iniciativas por ano de implementação

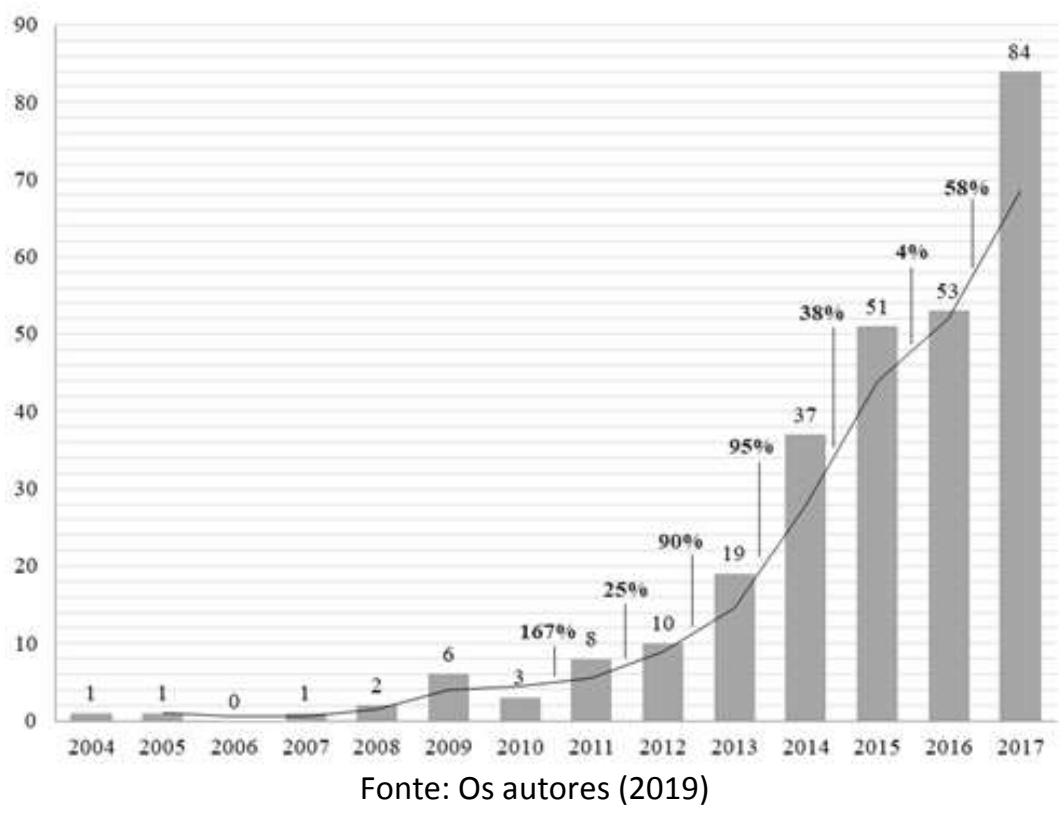

Perspectivas em Gestão \& Conhecimento, João Pessoa, v. 10, n. 2, p. 159-179, maio/ago. 2020. 
É interessante observar que o conceito de smart city está relacionado a projetos há 13 anos no Brasil, embora nos cinco primeiros anos o valor seja incipiente. $\mathrm{O}$ ano de 2006, por exemplo, não apresentou nenhum resultado. Após isso, o valor é sempre crescente a cada ano, com exceção do ano de 2010 , que apresentou queda de $50 \%$ em relação ao ano de 2009 . No entanto, os resultados apontam para uma significativa concentração de iniciativas nos últimos quatro anos (225, o que corresponde a $81,5 \%$ do total), o que colabora para evidenciar a emergência da temática e da veiculação do conceito no Brasil. Isso sugere, também, que o conjunto de atores-chave das últimas duas gestões esteve mais atento a essa temática.

As taxas de crescimento entre os anos indicam, em primeiro lugar, uma estagnação nos projetos entre os anos de 2015 e 2016, o que pode ser explicado pela crise econômica pela qual vinha passando o país. Além disso, pode-se observar que as maiores porcentagens de crescimento ocorrem no início das gestões municipais (iniciadas em 2009, 2013 e 2017); isso pode sugerir a preocupação com o fomento às iniciativas como estratégicas de marketing de gestão. Além disso, geralmente os períodos finais das gestões municipais são marcados por menor quantidade de recursos e desaceleração na implementação de projetos. O ano de 2017 recebe especial atenção, por, num período de 7 meses concentrar um número de iniciativas mais elevado do que nos 12 meses dos demais anos. No futuro, uma atualização dessa pesquisa poderá confirmar esse crescimento ou indicar uma tendência de estabilização, ou mesmo surgimento de um novo conceito para qualificar a relação cidade e TICs.

É, também, interessante observar que a crise político-econômica pela qual o país vinha passando desde meados de 2015 não parece ter afetado a implementação de projetos, em termos de quantidade absoluta. Não é possível afirmar, no entanto, se houve diminuição dos valores de investimentos dos projetos nesse período, pois essa grandeza não foi avaliada na pesquisa, uma vez que na maioria das vezes esse tipo de informação não estava disponibilizada nas fontes pesquisadas.

Os dados foram analisados, ainda, no sentido de evidenciar qual a relação entre as categorias dos projetos, os anos e o local de implantação, cenário apresentado na Gráfico 3.

Os resultados apontam que a categoria de eventos/feiras é uma das responsáveis pelo aumento do número de iniciativas nos anos de 2016 e 2017, com presença significativa nesses dois anos (equivalente a aproximadamente um terço das iniciativas de 2016 e um quarto das iniciativas de 2017). Novamente, evidencia o esforço ou a necessidade da discussão do conceito de smart city nas cidades brasileiras, embora não signifique um aumento no número de ações oriundas dessas discussões. Além disso, o resultado sugere uma primeira hipótese de que há uma maior facilidade na realização desse tipo de iniciativa, por serem episódios datados, com menores custos e sem comprometimento além do discurso, além de representarem um meio de visibilidade para o mercado de tecnologias setoriais urbanas para as grandes empresas deste ramo. Uma segunda hipótese é que iniciativas do tipo evento/feira podem ser uma maneira de introdução e de aproximação com o conceito de smart city, no sentido de criar uma cultura interna de tratamento do conceito, que seja perene independente das transições de gestão. Ambas as hipóteses demandariam uma análise mais aprofundada e contextualizada. 
Gráfico 3 - Distribuição de categorias por ano

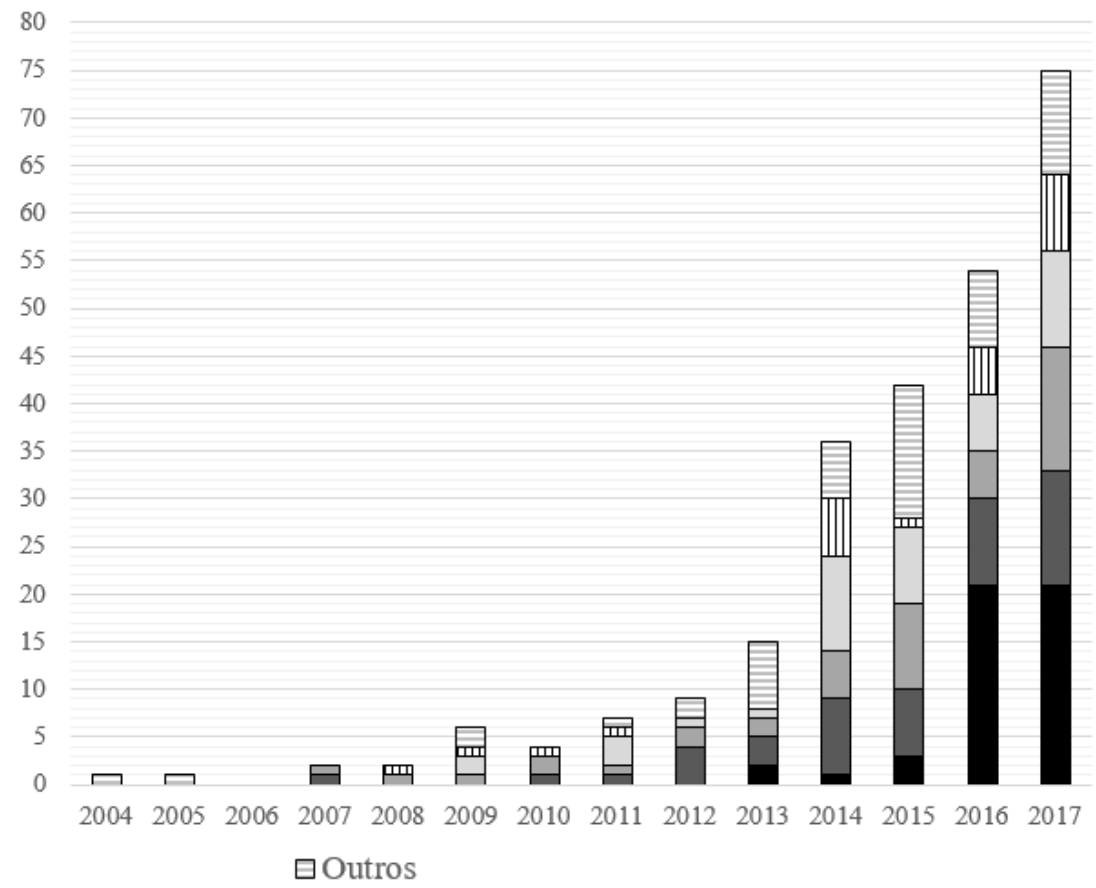

凹Meio ambiente e sustentabilidade

$\square$ Digitalização de processos e práticas

$\square$ Vigilância e segurança pública

$\square$ Mobilidade

- Evento/feira

Fonte: Os autores (2019)

Nota-se que os Parques Tecnológicos ou Ecossistemas de Inovação estão presentes em quase todos os anos, desde o início da série. Isso pode significar que estes itens são considerados como um paradigma, que as gestões procuraram implantar, possivelmente porque são pontos bem aceitos pelos atores envolvidos e tem apoio ou financiamento da iniciativa privada.

As categorias mobilidade e vigilância/segurança pública aparecem com relevância em quase todos os anos, desde 2010, o que reforça a associação dessas duas demandas ao conceito de smart city. É possível que isso derive do aumento da demanda por segurança pública, em função da violência crescente. Ou seja, a gestão precisa incluir no discurso que está fazendo algo, mesmo que na prática seja algo incipiente, porém com visibilidade.

A digitalização de práticas é, também, uma categoria presente nos projetos desde 2009, o que reforça a noção de associação comum do conceito de inteligência urbana à digitalização e às práticas digitais. Isso pode sugerir que o conceito ainda possui uma visão tecnicista por parte dos gestores e atores relacionados às implementações. Pode também estar atrelado a um discurso de marketing que preconize as tecnologias como solucionadoras dos problemas. Porém, essa é uma etapa anterior à veiculação do discurso de marketing preconizado por Aizadeh (2017) e Greenfield (2013), já que se trata de uma estruturação inicial (isso não exclui, porém, a possibilidade posterior de ser transformada, também em marketing urbano). A presença dessa hipótese, no entanto, pode variar conforme a região do país, já que a distribuição das temáticas ocorre de modo heterogêneo (ver Gráfico 4). 


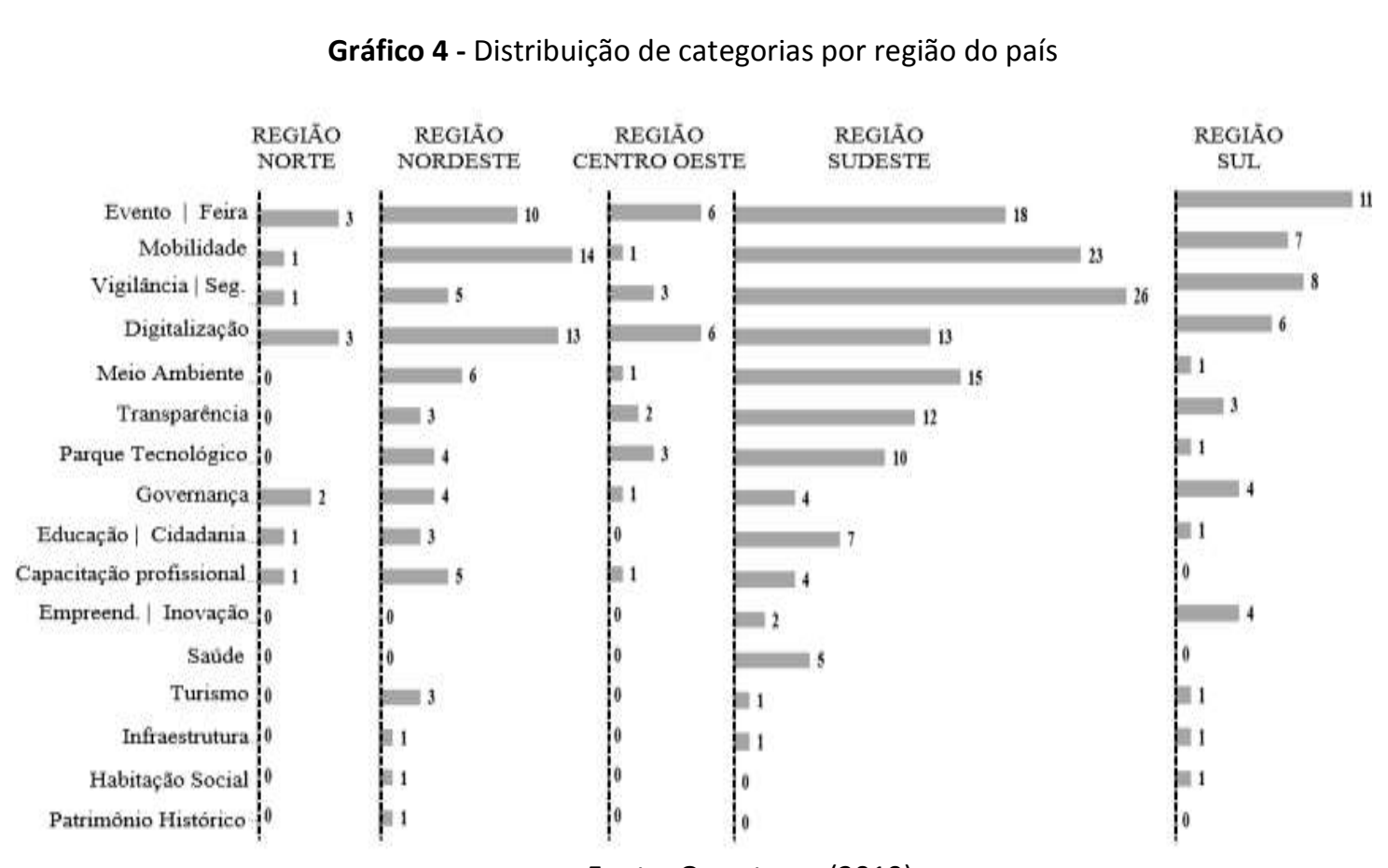

Fonte: Os autores (2019)

Essa discrepância fica visível ao observar que, no Sudeste, por exemplo, a categoria digitalização aparece com menor incidência, o que pode sugerir que as prefeituras dessa região já trabalharam a questão e buscam aprimoramento em outros setores. No Norte e Centro-Oeste a incidência é maior, o que sugere a necessidade desse aprimoramento inicial para o desenvolvimento. Daí supõe-se forte correlação entre infraestrutura e digitalização. É consenso de que em projetos de smart city, há uma primeira necessidade de se ter a infraestrutura básica, para que depois seja pensado em projetos de inteligenciamento urbano (ERSOY, 2017). Uma possível inferência é que, com a infraestrutura deficiente, um ponto fraco em diversas cidades brasileiras, a digitalização é uma melhoria de menor custo. Em reflexo ao que foi apontado no item 2, observa-se que em algumas cidades, as ações de marketing podem estar considerando essa etapa já superada, voltando-se, assim, para outros âmbitos.

A análise panorâmica permite verificar um relativo espelhamento entre a teoria acerca do conceito de smart city e disseminação por meio de projetos nas maiores cidades brasileiras. Isso é especialmente visível na presença de variadas áreas de foco de atuação e nas discrepâncias que surgem para determinadas tipologias projetuais em diferentes recortes geográficos - o que confirma a dificuldade de precisão conceitual e a necessidade de adequação ao contexto.

\section{CONSIDERAÇÕES FINAIS}

A presente pesquisa objetivou avaliar o fenômeno das smart cities no Brasil pelo estereótipo apresentado a partir de um diagnóstico exploratório e panorâmico das iniciativas assim denominadas nas maiores cidades brasileiras, por meio da síntese e da aplicabilidade do conceito. Metodologicamente, a pesquisa estruturou-se a partir de um levantamento bibliográfico-documental das iniciativas presentes nas cem maiores cidades brasileiras, categorizadas conforme tipologias de projetos e distribuição geográfico-temporal.

Discutiu-se que o conceito de smart city vem acompanhado de uma amálgama de fatores, entendimentos, termos correlatos e aplicabilidades, o que torna difícil 0 reconhecimento do que pode ser considerado inteligente no processo de gestão urbana. 
Os resultados mostraram que as iniciativas brasileiras autodenominadas smart city apresentam-se como ações relativas às mais diversas temáticas, refletindo a amálgama conceitual considerada por autores como Angelidou (2014), Albino, Berardi e Dangelico (2015), Aldairi e Tawalbeh (2017), Bibri e Krogstie (2017) e Cassandras (2016). A metodologia aplicada não permitiu verificar se há a relativa separação entre projetos mais tecnocêntricos ou mais antropocêntricos, como postulado por Kitchin (2014) e Graham e Marvin (1996). No entanto, observou-se que nas maiores cidades brasileiras os projetos smart city estão voltados, essencialmente para a promoção de eventos e feitas, para soluções de mobilidade e de vigilância, e para a digitalização de processos e práticas. Isso limita bastante o que chamamos de estereótipo das smart cities em poucas tipologias predominantes provavelmente pautadas pelo mercado das tecnologias setoriais urbanas e por tecnologias de gestão inteligente, bem como demandas por soluções rápidas e "mágicas" para problemas tradicionais das cidades brasileiras (como violência urbana, trânsito, e a má gestão).

A hipótese inicial de pesquisa pressupôs que o fenômeno de smart cities desencadeiase no Brasil mais como um processo de atualização de práticas de gestão, por meio da adoção de tecnologias digitais, do que como um encadeamento de utilização estratégicas das ferramentas na definição de agendas de governança. Os resultados desse estudo refletiram, de certa forma, essa hipótese, pois observou-se que os projetos estão, em grande parte, associados a um processo de reestruturação e de atualização de práticas com a utilização de novas tecnologias, e não necessariamente como um modelo totalmente original de gestão urbana ou de planejamento territorial. No entanto, a presença de diversas outras temáticas projetuais sugere que, ao longo do tempo, pode existir uma tentativa de caminhar entre um entendimento mais tecnocêntrico para um entendimento mais antropocêntrico - hipótese a ser confirmada em estudos futuros.

A principal controvérsia estabelecida nesse contexto é a que diz respeito à forma como a prática e implementação da política smart city são traduzidas para o entendimento da gestão. Embora esse tipo de levantamento não seja suficiente para identificar em totalidade essa convergência, pode-se discutir a respeito das políticas por demanda x políticas por oferta. Fica o questionamento: o entendimento do conceito de smart city tem sido anterior, posterior ou simultâneo à implementação prática da solução, da inovação ou da estratégia? Nesse sentido, faz-se necessário a coerência entre a concepção conceitual, a disseminação e veiculação da mesma e a aplicação estratégica.

Um segundo questionamento refere-se ao fato de a cidade estar se tornando cada vez menos um locus de ação e vivência para tornar-se produto. A partir da revisão teórica e dos resultados obtidos, sugere-se que esse é um fenômeno que, a exemplo de outros países, também pode estar ocorrendo no Brasil, fato que sugere a manifestação das teorias de Klauser, Paasche e Söderström (2014) e de Vanolo (2014), que postulam o discurso smart city pautado também sobre disputas de mercado e de poder.

O estudo permite, ainda, uma reflexão a respeito de metodologias científicas de investigação sobre fenômenos tão complexos quanto as smart cities. Reconhece-se a limitação de que, sendo este um estudo exploratório, não permite inferências sobre o nível de entendimento do conceito de smart city nos projetos analisados, ou sobre as premissas conceituais que podem ter embasado cada uma das iniciativas. No entanto, investigações como a aqui apresentada contribuem para a compreensão panorâmica da veiculação e da disseminação do conceito, considerando diferenças de recorte geográfico e temporal. Isso significa que o fenômeno das smart cities não pode ser encerrado em uma única forma de abordagem metodológica, mesmo que ela seja validada - como no caso desse estudo - por resultados que confirmem parcialmente a teoria em torno do conceito. Associando a isso o fato de que o fenômeno está, também, vinculado a uma adoção terminológica específica, mutável a cada época, o resultado é a necessidade constante da realização de estudos sob

Perspectivas em Gestão \& Conhecimento, João Pessoa, v. 10, n. 2, p. 159-179, maio/ago. 2020. 
múltiplas perspectivas para que o conceito e seus condicionantes tangenciais seja melhor compreendido e ajude, efetivamente, na construção de agendas urbanas mais efetivas.

Nesse sentido, estudos futuros serão necessários no sentido de atualizar a pesquisa, dada a constante mutação dos conceitos-chave que compõem o tema. Além disso, a proposta pode ser aprofundada e ampliada geográfica e temporalmente, e, nesse sentido, uma sugestão seria aprofundar o estudo do grau de dependência dos processos em relação às TICs, com o intuito de investigar se elas se apresentam imperativamente como soluções para as demandas urbanas.

\section{REFERÊNCIAS}

ALBINO, V.; BERARDI, U.; DANGELICO, R. M. Smart Cities: Definitions, Dimensions, Performance, and Initiatives. Journal of Urban Technology, n. 22, v.1, 2015, p.3-21. Disponível em: http://dx.doi.org/10.1080/10630732.2014.942092. Acesso em: nov. 2017.

ALDAIRI, A; TAWALBEH, L. Cyber Security Attacks on Smart Cities and Associated Mobile Technologies. Procedia Computer Science, 109c, 2017, p. 1086-1091. Disponível em: < https://doi.org/10.1016/j.procs.2017.05.391. Acesso em:nov./2017.

ALIZADEH, T. An investigation of IBM's Smarter Cites Challenge: What do participating cities want? Cities, n. 63, 2017, p. 70-80. Disponível em: http://dx.doi.org/10.1016/i.cities.2016.12.009. Acesso em: jul./2020.

ANGELIDOU, M. Smart city policies: A spatial approach. Cities, n.41, 2014, S3-S11. Disponível em: https://doi.org/10.1016/j.cities.2014.06.007. Acesso em: nov. 2017.

AURIGI, A. Making the Digital City: the early shaping of urban internet space. Hampshire: Ashgate, 2005.

BESSELAAR, P. V. D. Local information and communication infrastructures: an introduction (p.1-16) In: Besselaar, P. V. D.; Koizumi, S. Digital Cities III: Information Technologies for Social Capital - Cross-cultural Perspectives. Series Lecture Notes in Computer Science, 2013, v. 3081.

BIBRI, S. E.; KROGSTIE, J. Smart sustainable cities of the future: An extensive interdisciplinary literature review. Sustainable Cities and Society, n. 31, 2017, p.183-212. Disponível em: https://doi.org/10.1016/i.scs.2017.02.016. Acesso em: nov. 2017.

BOYER, M. C. The imaginary real world of cybercities. Assemblage, 1992, n.18, pp.114-127.

BUSINESSWIRE. Navigant Research's Smart City Tracker 2 Q19 Highlights 443 Projects Spanning 286 Cities Around the World. Publicado em 20 de junho de 2019. Disponível em: < https://www.businesswire.com/news/home/20190620005092/en/NavigantResearch\%E2\%80\%99s-Smart-City-Tracker-2Q19-Highlights> Acesso em: jul/2020.

CALZADA, I.; COBO, C. (2015). Unplugging: Deconstructing the Smart City, Journal of Urban Technology, n. 22, v.1, p.23-43. 
CASSANDRAS, C. G. Smart Cities as Cyber-Physical Social Systems. Engineering, n. 2, 2016, p.156-158. Disponível em: http://dx.doi.org/10.1016/J.ENG.2016.02.012. Acesso em: nov. 2017.

DELARBRE, R. T. En la era de la posverdad: La manipulación de las redes sociodigitales. TELOS, 107, p. 8-11. Disponível em: https://pdfs.semanticscholar.org/2f1d/a5ecb65f98e895a1ca251807d1aacc794b1e.pdf\#page=1 12. Acesso em: jul. 2020.

DONATH, J. S. Inhabiting the Virtual City: The design of social environments for electronic communities. Tese de doutorado. Philosophy, Massachusetts Institute of Technology, 1996. Disponível

em: https://www.researchgate.net/publication/37991360 Inhabiting the virtual city the design of social environments for electronic communities. Acesso em: dez.2015.

EISENBERG, J. Internet Popular e democracia nas cidades. In Revista Informática Pública, ano 1, vol.1, Belo Horizonte, 1999, p. 07-24. Disponível em: http://bogliolo.eci.ufmg.br/downloads/EISENBERG\%20Internet\%20Popular.pdf. Acesso em: nov. 2015.

ERSOY, A. Smart cities as a mechanism towards a broader understanding of infrastructure interdependencies. Regional Studies, Regional Science, 2017, v.4, n.1, p. 26-31. Disponível em: http://dx.doi.org/10.1080/21681376.2017.1281154. Acesso em: nov. 2017.

FARINIUK, T. M. D. A construção multifacetada do conceito de smart city: o panorama brasileiro e o caso de Curitiba - Paraná. Tese de Doutorado. Programa de Pós-graduação em Gestão Urbana. Pontifícia Universidade Católica do Paraná. 2018.

FIRMINO, R. Building the Virtual City: the Dilemmas of Integrative Strategies for Urban and Electronic Spaces. Tese de Doutorado. University of Newcastle. Newcastle, 2004.

FLOCH-PRIGENT, P. Le. The Vitruvian Man: an anatomical drawing for proportions by Leonardo Da Vinci. Morphologie, n.92, 2008, p. 204-209. Disponível em: http://europepmc.org/abstract/med/18951824. Acesso em: nov. 2017.

FONTELLES, M. J.; SIMÕES, M. G.; FONTELLES, S. H. Metodologia da pesquisa científica: diretrizes para a elaboração de um protocolo de pesquisa. Núcleo de Bioestatística Aplicado à pesquisa da Universidade da Amazônia - UNAMA, 2009. Disponível em: http://files.bvs.br/upload/s/0101-5907/2009/v23n3/a1967.pdf. Acesso em: dez. 2015.

FOUCAULT, M. Segurança, território, população. Curso no Collège de France (1977-1978). São Paulo: Martins Fontes, 2008.

GANDY, M. Cyborg Urbanization: Complexity and Monstrosity in the Contemporary City. International Journal of Urban and Regional Research, v. 29, mar. 2005, p. 26-49. Disponível em: http://www.matthewgandy.org/datalive/downloadfiles/ijurr.pdf. Acesso em: set. 2015.

GIFFINGER, R.; FERTNER, R.; KRAMAR, H.; KALASEK, R.; PICHLER-MILANOVIC, N. MEIJERS, E. Smart Cities - Ranking of European medium-sized cities. Vienna University of Technology, 2007.

Perspectivas em Gestão \& Conhecimento, João Pessoa, v. 10, n. 2, p. 159-179, maio/ago. 2020. 
GREENFIELD, A. Against the Smart City: The city is here for you to use, Book 1. Do projects. ebook Kindle. 2013.

GRAHAM, S.; \& MARVIN, S. Telecommunications and the city: electronic spaces, urban places. London: Routledge, 1996.

GUERREIRO, E. P. Cidade digital: infoinclusão social e tecnologia. São Paulo: SENAC, 2006.

HARVEY, D. A produção capitalista do espaço. São Paulo: Annablume, 2005.

HOLLANDS, R. G. Will the real smart city please stand up? City, 2008, v. 12, n. 3, p. 303-320. Disponível em: https://doi.org/10.1080/13604810802479126. Acesso em: fev./2019.

IBGE - INSTITUITO BRASILEIRO DE GEOGRAFIA E ESTATÍSTICA. IBGE Cidades. Projeção Populacional para 2018. Disponível em: http://www.cidades.ibge.gov.br/. Acesso em: jul. 2019.

INFSO Internet of Things in 2020: A Roadmap for the Future. Workshop Report, EC INFSO and EPoSS, Belgium, 2008.

KITCHIN, R. From a single line of code to an entire city: reframing thinking on code and the city. In Code and the City workshop, 3rd-4th September 2014, Programmable City, NIRSA, National University of Ireland Maynooth.

KOMNINOS, N. (2011). Intelligent cities: Variable geometries of spatial intelligence. Intelligent Buildings International, n. 3, 172-188. Disponível em: < https://doi.org/10.1080/17508975.2011.579339 > Acesso em: fev./2019.

KLAUSER, F.; PAASCHE, T.; \& SÖDERSTRÖM, O. Michel Foucault and the smart city: power dynamics inherent in contemporary governing through code. Environment and Planning $D$, 2014. $32 \quad$ (5), 869-885. Disponivel em: https://www.researchgate.net/publication/268630150 Michel Foucault and the smart city power dynamics inherent in contemporary governing through code. Acesso em: nov. 2017.

LEMOS, A. L. M. Cidades inteligentes: De que forma as novas tecnologias -como a computação em nuvem, o Big Data e a Internet das Coisas - podem melhorar a condição de vida nos espaços urbanos? Gvexecutivo, 2013, n.12, v.2, p. 46-49.

LEMOS, A. L. M. Cibercultura: Tecnologia e Vida Social na Cultura Contemporânea. Porto Alegre: Sulina, 2002.

LLACUNA, M. M.; COLOMER-LLINÀS, J.; MELÉNDEZ-FRIGOLA, J. Lessons in urban monitoring taken from sustainable and livable cities to better address the Smart Cities initiative. Technological Forecasting \& Social Change, v.90, 2015, p.611-622. Disponível em: http://www.sciencedirect.com/science/article/pii/S0040162514000456. Acesso em: set. 2016. 
LUQUE-AYALA, A.; MARVIN, S. Developing a critical understanding of smart urbanism? Urban Studies, 2015, vol.52, n. 12, p.2105-2116. Disponível em: https://doi.org/10.1177/0042098015577319 Acesso em: nov. 2017.

Maček, A., Ovin, R., \& Starc - Peceny, U. Smart Cities Marketing and Its Conceptual Grounds. Naše gospodarstvo/Our Economy, 2019, v.65, n.4, p. 110-116. Disponível em: <10.2478/ ngoe-2019-0024> Acesso em: jul/2020.

MARTINS, G. A. Estudo de caso: uma estratégia de pesquisa. São Paulo: Atlas, 2006.

MASCARENHAS, G.; BORGES, F. C. S. Entre o empreendedorismo urbano e a gestão democrática da cidade: dilemas e impactos do Pan-2007 na Marina da Glória. Esporte e Sociedade, n. 10, nov. 2008-Fev.2009. Disponível em: http://www.uff.br/esportesociedade/pdf/es1004.pdf. Acesso em: jul.2020.

MITCHELL, W. J. City of Bits: Space, Place and the Infobahn. Cambridge, MA: MIT Press, 1995.

MITCHELL, W. J. Me++: the cyborg self and the networked city. Cambridge, The MIT Press, 2003.

NETTO, V. M. Cidade e sociedade: as tramas da prática e seus espaços. Porto Alegre: Sulina, 2014.

PECK, J.; TICKELL, A. Neoliberalizing Space. Antipode, v.34, n.3, 2002, p.380-404.

ROLNIK, RI.; SOMEKH, N. Governar as metrópoles: dilemas da recentralização. Cadernos Metrópole, $\quad \mathrm{n}$. $8,2002.20 \mathrm{em}$ : http://revistas.pucsp.br/index.php/metropole/article/view/9253/6865. Acesso em: ago. 2016.

ROSSI, P. H.; WRIGHT, J. D. \& ANDERSON, A. B (eds.) Handbook of survey research. New York: Academic Press, 2013.

SALGADO, M. de M. A inteligência na sociedade positiva: dos humanos às cidades (p.38-49). 2016.. In: SANTAELLA, L. (org). Cidades inteligentes: por que, para quem? São Paulo: Estação das Letras e Cores, 2016.

SOUZA, R. J. CATALÃO, I. Da "cidade-cyborg" à "atmosfera-cyborg": contribuições à análise do espaço e do clima urbanos. Sociedade \& Natureza, v. 28, n. 2, 2016, pp. 199-213. Disponível em: https://www.redalyc.org/pdf/3213/321348348003.pdf. Acesso em: jul. 2019.

TUWIEN - Technische Universität Wien. European Smart Cities 4.0. 2016. Disponível em: http://www.smart-cities.eu/?cid=01\&ver=4 Acesso em: nov. 2017.

URRY, J. Sociology beyond societies: mobilities for the twenty-first century. Routledge, London, 2000.

VANOLO, A. Smartmentality: The Smart City as Disciplinary Strategy. Urban Studies, v. 51, n.5, abr.2014, p. 883-898. Disponível em: https://doi.org/10.1177/0042098013494427 Acesso em: set. 2018. 
ZHAO, P. Building knowledge city in transformation era: Knowledge-based urban Development in Beijing in the context of globalisation and decentralisation. Asia Pacific Viewpoint, v.51, n.1, abr./2010, p. 73-90. Disponível em: http://onlinelibrary.wiley.com/doi/10.1111/j.14678373.2010.01415.x/abstract Acesso em: mar. 2016.

Artigo recebido em 25/07/2019 e aceito para publicação em 21/07/2020 